\title{
Evolution of residual stresses during short time nitriding of 33CrMoV12-9 steel grade.
}

\author{
G. Fallot ${ }^{1,2, a^{*}}$, S. Jégou ${ }^{1, b}$ and L. Barrallier ${ }^{1, c}$ \\ ${ }^{1}$ MSMP Laboratory, Arts et Metiers ParisTech, Aix-en-Provence, France \\ ${ }^{2}$ Airbus Helicopters, Marignane, France

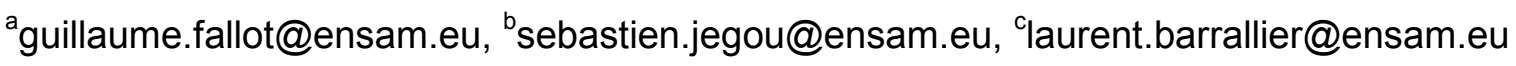

Keywords: Nitriding, residual stresses, phase transformations, iron alloys, precipitation.

\begin{abstract}
The evolution of residual stresses during short time gas nitriding of 33CrMoV12-9 steel grade is studied. It aims understanding the influence of nitriding parameters (temperature $T$ and nitriding potential $\mathrm{Kn}$ ) on the generation and evolution of residual stresses in the very first stage of nitriding. The samples are gas nitrided using a thermobalance during $2 \mathrm{~h} 30$ and 5 hours for various temperatures and nitriding potentials. Residual stress analyses are carried out by laboratory X-ray diffraction.
\end{abstract}

\section{Introduction}

Nitriding is a thermochemical surface treatment involving the diffusion of nitrogen and generating a hardening effect combined to compressive residual stresses [1]. This process is used to improve fatigue life, tribological and anti-corrosion properties of iron-based alloys [2]. At nitriding temperature $\left(400\right.$ to $\left.600^{\circ} \mathrm{C}\right)$, the generation of residual stresses occurs simultaneously with hardening. It finds its origins in volume changes accompanying phase transformations during nitrogen diffusion. The volume change is a consequence of lattice distortions, molar volumes and thermal expansion coefficients between precipitates and the ferritic matrix [3-4].

The influence of nitriding parameters (temperature and nitriding potential) on the evolution of residual stresses has been studied by Barralis [4] for long time gas nitriding of 33CrMoV12-9 steel grade and by Jegou [6] on a ternary Fe-3\%Cr- $0.345 \% \mathrm{C}$ alloy. The evolution of residual stresses during the nitriding treatment is the consequence of the microstructural evolutions through the case due to the co-diffusion of nitrogen and carbon. The resulting precipitation kinetic modifies the volume fraction of precipitates as well as the induced volume variation [7].

The present work aims studying the generation of residual stresses in the very first stage of nitriding of the 33CrMoV12-9 steel grade. Various nitriding parameters ( $T$ and $K n$ ) are considered.

\section{Experimental Procedure}

\section{Material, sample preparation and nitriding process}

The composition of the 33CrMoV12-9 steel grade, quenched and annealed at $620{ }^{\circ} \mathrm{C}$, used during this study is given in Table 1 . Before gaz nitriding, rectangular specimens $\left(17 \times 13 \times 5 \mathrm{~mm}^{3}\right)$ are machined on all sides and cleaned by ultrasounds within ethanol.

Nitriding experiments were performed in a Setsys Evolution thermobalance with a vertical alumina-tube furnace controlled within $\pm 3{ }^{\circ} \mathrm{C}$ in the isothermal zone. The nitriding atmosphere was composed of a gas mixture of $\mathrm{NH}_{3}-\mathrm{N}_{2}-\mathrm{H}_{2}$. The flow rate of each gas was adjusted separately using mass-flow controllers. The nitriding potential $K n$ is given by the composition of gas mixtures as
follows (eq.1):
$K n=P_{N H 3} /\left(P_{H_{2}}\right)^{3 / 2}$ eq 1 
The nitriding parameters of each sample are given in Table 2. Figure 1 shows the position of each treatment on the Lehrer diagram [8]. In case of pure iron, it gives the phase in equilibrium with the nitriding gas atmosphere depending on the temperature $T$ and potential $K n$. The dashed line on the Lehrer diagram corresponds to the interface between $\alpha-\mathrm{Fe}$ and $\gamma^{\prime}-\mathrm{Fe}_{4} \mathrm{~N}$ as experimentally obtained for the 33CrMoV12-9 grade steel (see Fig.1) [8]. After nitriding, the specimens were cooled at $20^{\circ} \mathrm{C} \cdot \mathrm{min}^{-1}$ to room temperature in a flow gas of nitrogen.

The nitrided samples were cut in two pieces, grinded and polished up to a $0.05 \mu \mathrm{m}$ colloidal silica suspension. The nitrided cases were observed by scanning electron microscopy using a backscattered electrons mode (JEOL 7001F SEM-FEG).

\section{Stress analysis}

Residual stress analyses were carried out by laboratory X-ray diffraction using a Siemens D500 diffractometer with $\mathrm{Cr}-\mathrm{K}_{\alpha}$ radiation $(\lambda=0.228975 \mathrm{~nm})$ on the $\{211\}$ diffracting plane of $\alpha-\mathrm{Fe}$. The gauge volume was defined by a $3 \mathrm{~mm}$ diameter tape mask. The $\sin ^{2} \Psi$ method was used to determine the mean residual stresses in order to determine $\sigma_{\mathrm{XRD}}^{\alpha}=\left(\sigma_{\mathrm{xx}}^{\alpha}-\sigma_{\mathrm{zz}}^{\alpha}\right)$ in the ferritic matrix within the depth of the case. Radiocristallographic stiffness are calculated with Kröner-Elshelby model and used to determine the stress $\left(\mathrm{S}_{1}{ }^{\{211\}}=-1.2510^{-6} \mathrm{MPa}^{-1}, 1 / 2 \mathrm{~S}_{2}{ }^{\{11\}}=5.8510^{-6} \mathrm{MPa}^{-1}\right)$. Depth profiling was performed using electro-chemical surface layer removal (Struers Lectropol 5).

Table 1: Composition of the 33CrMoV12-9 steel grade.

\begin{tabular}{|c|c|c|c|c|c|c|c|c|}
\hline wt.\% & $\mathrm{C}$ & $\mathrm{Si}$ & $\mathrm{Mn}$ & $\mathrm{Cr}$ & $\mathrm{Mo}$ & $\mathrm{Ni}$ & $\mathrm{V}$ & $\mathrm{Fe}$ \\
\hline 33CrMoV12-9 & 0.34 & 0.23 & 0.45 & 3.10 & 0.91 & 0.22 & 0.21 & Balance \\
\hline
\end{tabular}

Table 2: Nitriding time, temperature and potential for gas nitriding of 33CrMoV12-9 steel grade.

\begin{tabular}{|c|c|c|}
\hline Time $[\mathrm{h}]$ & Temperature $\left[{ }^{\circ} \mathrm{C}\right]$ & $\mathrm{Kn}\left[\mathrm{atm}^{-1 / 2}\right]$ \\
\hline $5 \mathrm{~h}$ & 550 & 0.30 \\
\hline $5 \mathrm{~h}$ & 550 & 0.79 \\
\hline $5 \mathrm{~h}$ & 550 & 3.65 \\
\hline $5 \mathrm{~h}$ & 550 & 13.77 \\
\hline $5 \mathrm{~h}$ & 520 & 3.65 \\
\hline $5 \mathrm{~h}$ & 480 & 3.65 \\
\hline $2 \mathrm{~h} 30$ & 550 & 3.65 \\
\hline
\end{tabular}

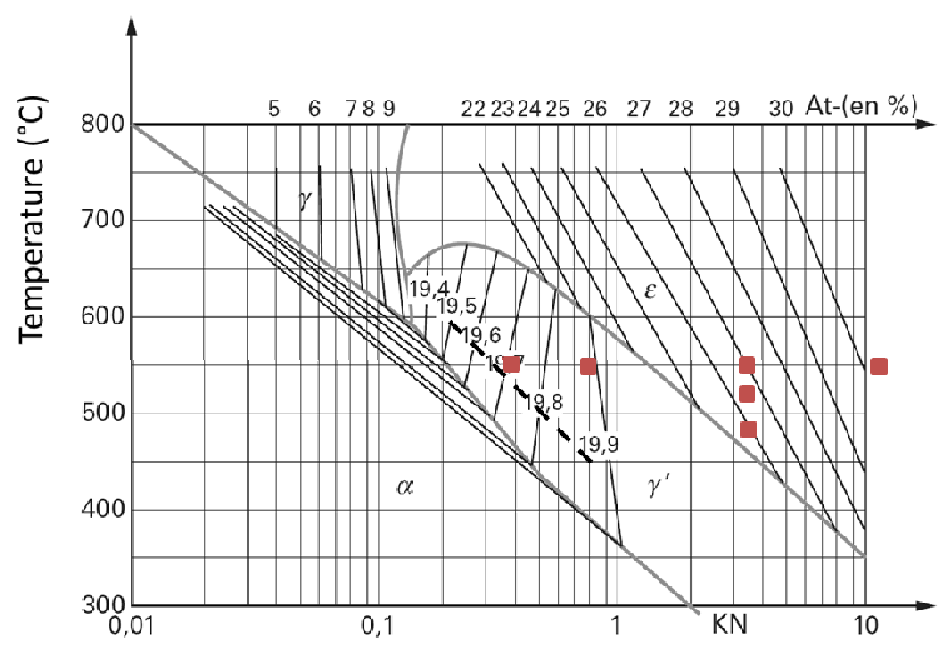

Figure 1: Lehrer diagram [8] and nitriding parameters of Table 2 as red points. The dashed line corresponds to the interface between $\alpha-\mathrm{Fe}$ and $\gamma^{\prime}-\mathrm{Fe}_{4} \mathrm{~N}$ as experimentally characterized. 


\section{Results and Discussion}

\section{Influence of the nitriding potential}

SEM micrographies (Figure 2) show that the thickness of the compound layer and precipitation of cementite at grains boundaries nearly parallel to the nitriding surface increase with the nitriding potential Kn. According to the chemical contrast, iron nitrides are also observed at grain boundaries at the interface between the compound and diffusion layer.

The in-depth stress profiles are given on Figure 3. The maximal compressive stress is of the same magnitude for all nitriding potentials after $5 \mathrm{~h}$ of nitriding at $550{ }^{\circ} \mathrm{C}$. The surface zone under compressive stresses increases with the nitriding potential, being almost similar for $K n=0.79$ and 3.65. The evolution of the compressive residual stress of the near surface is remarkable even after only $5 \mathrm{~h}$ of nitriding. Between 0 and $50 \mu \mathrm{m}$ in depth, residual stresses (taking the absolute value) change with the nitriding potential. For a given phase region of the Lehrer diagram, but decrease when changing from the $\gamma^{\prime}-\mathrm{Fe}_{4} \mathrm{~N}$ to the $\varepsilon-\mathrm{Fe}_{2-3} \mathrm{~N}$ region. These trends are similar to those found by Barralis for long time nitriding of the $33 \mathrm{CrMoV} 12-9$ grade. Table 3 show the Specific volume of the phase present in nitriding steel.

According to Dulcy et al., a low nitriding potential $(0.4<K n<2)$ induces a decarburization of the surface by the atmosphere whereas a high nitriding potential $(K n>2)$ induces a diffusion of carbon toward the core of the sample [8]. The effect of carbon diffusion on the generation and evolution of stress during nitriding were studied in previous works [6,7]. The precipitation of cementite at grain boundaries involves positive volume change (see Table 3) generating compressive residual stresses. During the transformation of cementite into $\gamma$ ' $-\mathrm{Fe}_{4} \mathrm{~N}$ nitride, the residual compressive stresses decreases (corresponding to the first point of the residual stress profile $K n=3.65$ ). The transformation of cementite into $\gamma^{\prime}-\mathrm{Fe}_{4} \mathrm{~N}$ nitride induces positive volume change that generate compressive residual stresses (corresponding to the first point of the residual stress $K n$ $=0.79$ ). The difference of the compressive stress near the surface between samples can thus be explain by different volume fraction of cementite and different stage of transformation from cementite into iron nitride. The positive volume change is higher for the transformation of cementite into $\gamma^{\prime}-\mathrm{Fe}_{4} \mathrm{~N}$. The increase of residual stresses just after the maximum of stress (depth $\left.>100 \mu \mathrm{m}\right)$ when increasing the nitriding potential suggests different precipitation kinetics due to the diffusion of nitrogen but also carbon. The diffusion of carbon toward the nitrogen diffusion front is more important for the sample nitrided at $K n=13.77$. It results in the precipitation of carbides $\mathrm{M}_{7} \mathrm{C}_{3}$, $\mathrm{M}_{23} \mathrm{C}_{6}$ or cementite depending on the content of nitrogen [7]. Such precipitation generates positive volume change and results in the generation of compressive stresses. According to Dulcy et al., the nitrogen concentration at the interface $\gamma^{\prime} / \alpha$ varies from $1.4 \%$ to $1.86 \%$ at $520{ }^{\circ} \mathrm{C}$ for a $K n$ going from 0.4 to 1.62 in the $33 \mathrm{CrMoV} 12-9$ steel grade [8]. This change in concentration, and there for the corresponding increase of the nitrogen flux, can explain the increase of the size of the surface zone under compressive stress between $K n=0.3$ and $K n=0.79$.

Table 3 : Specific volume of phases encountered within a nitrided case $(\mathrm{M}=\mathrm{Cr}, \mathrm{V}, \mathrm{Mo} . .$.$) [8].$

\begin{tabular}{|c|c|}
\hline Phase & Specific volume $\left(\mathrm{cm}^{3} \cdot \mathrm{kg}^{-1}\right)$ \\
\hline$\alpha-\mathrm{Fe}$ & 127.1 \\
\hline $\mathrm{M}_{3} \mathrm{C}$ & 130.9 \\
\hline$\gamma^{\prime}-\mathrm{Fe}_{4} \mathrm{~N}$ & 138.1 \\
\hline$\varepsilon-\mathrm{Fe}_{2-3} \mathrm{~N}$ & 138.7 \\
\hline Carbides $\left(\mathrm{M}_{7} \mathrm{C}_{3} \mathrm{M}_{23} \mathrm{C}_{6}\right)$ & 145.5 \\
\hline Nitrides $(\mathrm{CrN})$ & 161.3 \\
\hline
\end{tabular}



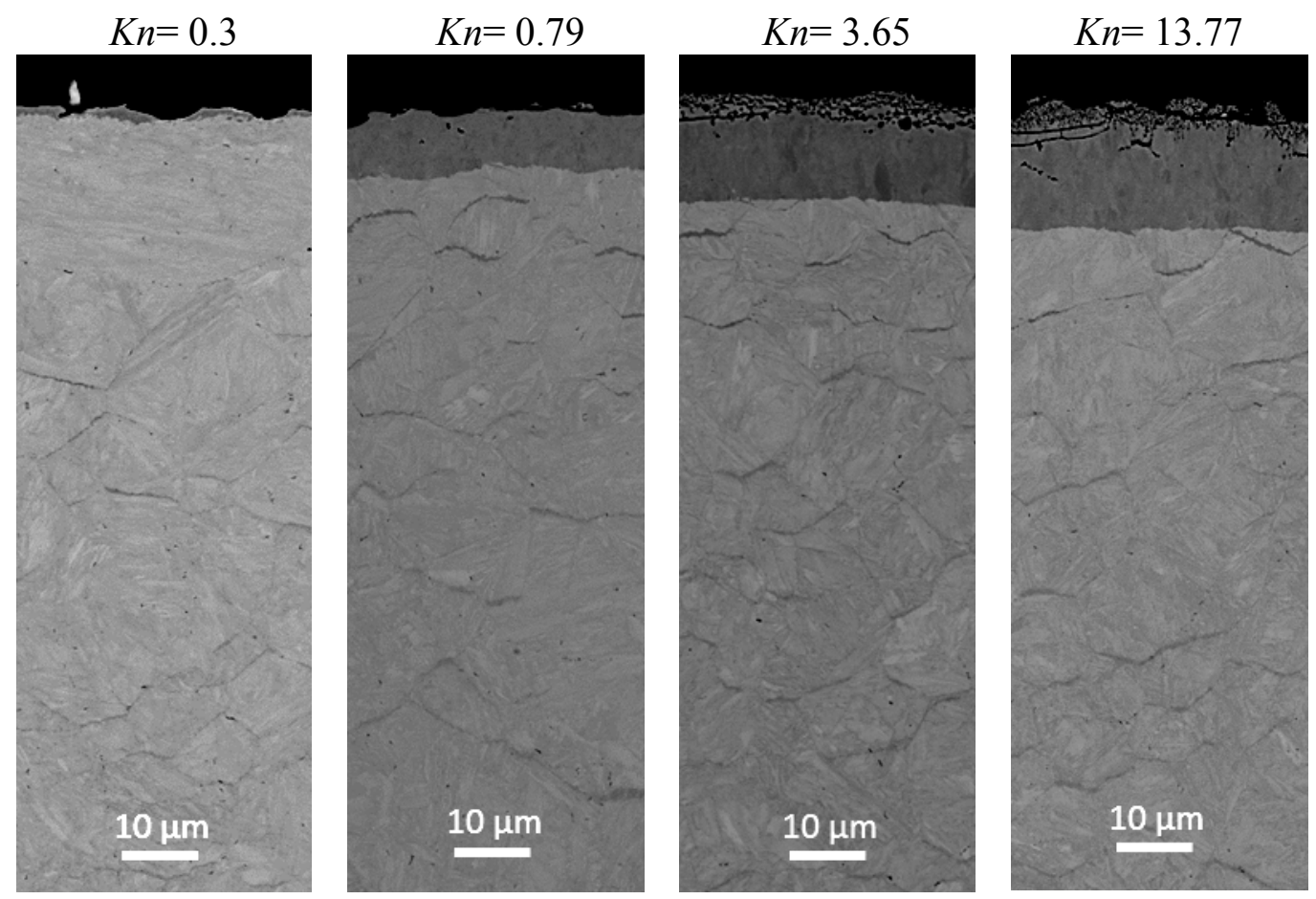

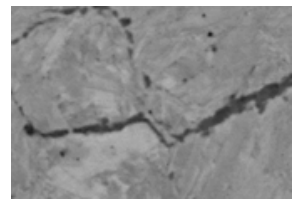

Nitride

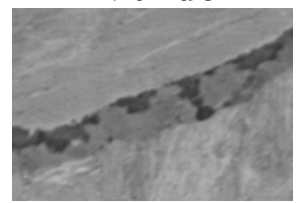

Nitride and

carbide

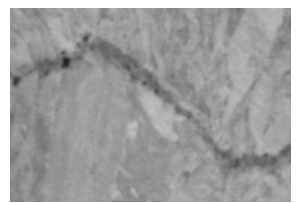

carbide

Figure 2 : SEM micrographies using backscattered electrons of the 33CrMoV12-9 steel grade nitrided at $550{ }^{\circ} \mathrm{C}$ during $5 \mathrm{~h}$.

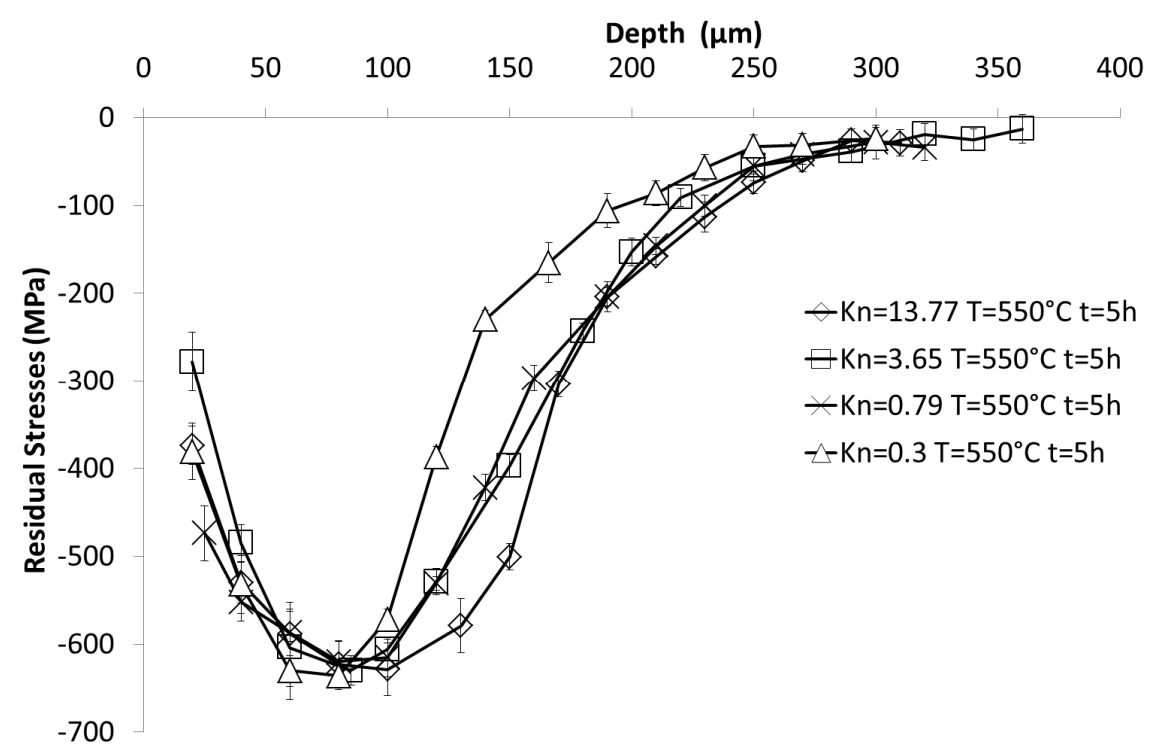

Figure 3: Influence of the nitriding potential on the mean residual stress of the ferritic matrix. Depth profiling of the $33 \mathrm{CrMoV} 12-9$ steel grade nitrided at $550{ }^{\circ} \mathrm{C}$ during $5 \mathrm{~h}$.

\section{Influence of the nitriding time}

Figure 5 gives the evolution of residual stresses in the ferritic matrix with the time of nitriding at $550{ }^{\circ} \mathrm{C}$ and for $K n=3.65$. In this case the maximal compressive stress decreases with the nitriding time. As could be expected, the depth affected by compressive residual stress increases with the treatment time. As previously, the compressive residual stress close to the surface decrease when the time increases due to the transformations of cementite into $\gamma^{\prime}-\mathrm{Fe}_{4} \mathrm{~N}$. This evolution in the stress profile with the treatment time can be attributed to the co-diffusion of nitrogen and carbon [7]. The 
diminution of the residual stress with the time can be due to an evolution of the precipitation during the nitriding.

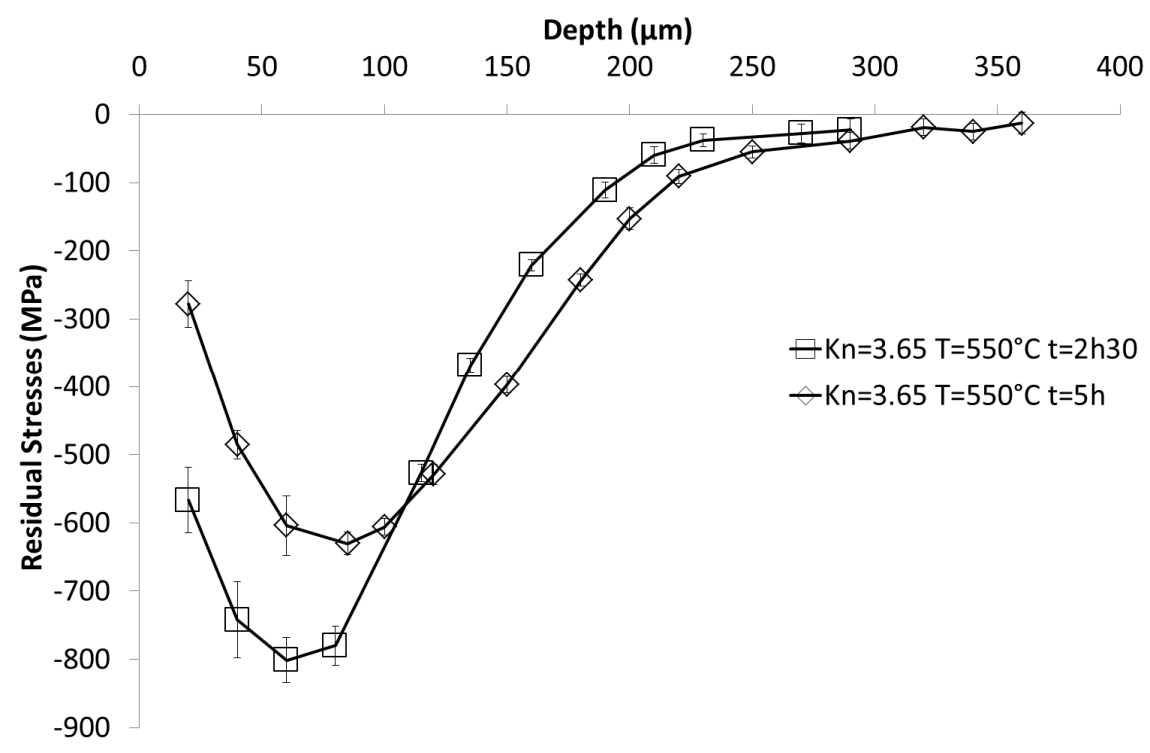

Figure 5: Influence of the nitriding duration on the mean residual stress of the ferritic matrix. Depth profiling of the $33 \mathrm{CrMoV} 12-9$ steel grade nitrided at $550{ }^{\circ} \mathrm{C}$ for $K n=3.65$.

\section{Influence of the nitriding temperature}

Figure 4 shows the in-depth evolution of residual stresses of the ferritic matrix with the nitriding temperature. Residual stresses (taking the absolute value) close to the surface highly decrease with the temperature, going from $1600 \mathrm{MPa}$ at $480{ }^{\circ} \mathrm{C}$ to $250 \mathrm{MPa}$ at $550{ }^{\circ} \mathrm{C}$. The maximal compressive stress decreases with the temperature. The surface zone under compressive stresses increases with temperature. This co-diffusion induces phase transformations, accompanied by positive volume change and the generation of compressive residual stresses. The evolution of the maximal compressive stress is due to a thermal relaxation and a change in the kinetics of phase transformation. As shown for long time nitriding, such evolution is characteristic of a change in the precipitation kinetics induced by the co-diffusion of nitrogen and carbon [7]. These results are similar to those found by Barralis for long time nitriding of the 33CrMoV12-9 steel grade.

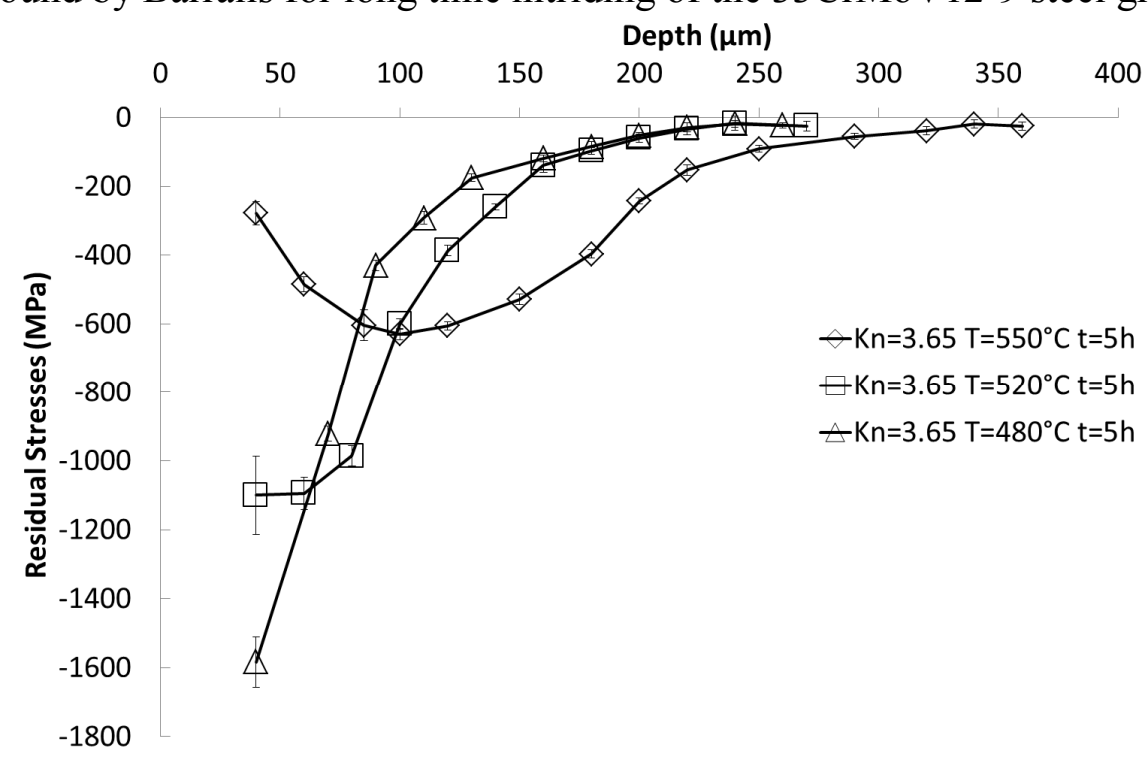

Figure 4: Influence of the nitriding temperature on the mean residual stress of the ferritic matrix. Depth profiling of the 33CrMoV12-9 steel grade nitrided during $5 \mathrm{~h}$ for $\mathrm{Kn}=3.65$. 


\section{Conclusion}

The influence of nitriding parameters (time, temperature, nitriding potential) on the residual stress generation and evolution was investigated for a nitrided 33CrMoV12-9 steel grade.

The nitriding potential modify the carbon distribution of the nitrided layer that increase the volume fraction of cementite precipitation. Increasing the nitriding potential beyond $K n=3.65$ permits to increase the surface zone under compressive stresses. The nitriding potential have no influence on the value of the maximum compressive stress.

The nitriding temperature activates the diffusion of nitrogen and carbon and accelerates the kinetics of phase transformations. Modifying the nitriding temperature permit to control the value of the maximum compressive stress and the size of the zone under compressive stress.

The nitriding time modify the value of residual stress close the surface, the value of the maximum compressive stress and the size of the under compressive stress.

The results found for short time nitriding are different to those found by Barralis for long time nitriding of the 33CrMoV12-9 steel grade [5]. However to explain the influence of nitriding parameters, more investigations are required in order to quantify the diffusion of carbon as well as the volume fraction of iron nitrides and cementite.

\section{References}

[1] Locquet J.N. Caractérisation métallurgiques et mécaniques de couches nitrurées, relation microstructure comportement. PhD thesis, ENSAM d'Aix-en-Provence, 1998.

[2] Basu A., Dutta Majumdar J., Alphonsa J., Mukherjee S., and Manna I. Corrosion resistance improvement of high carbon low alloy steel by plasma nitriding. Materials Letters, 2008.

[3] Barrallier L, Barralis J. Proceedings of ICRS4 aéronautiques. Traitement Thermique, 341, 2002. Baltimore, (MD) USA: Society for Experimental Mechanics Inc., 1994.

[4] Mittemeijer EJ. Proceedings of the symposium sponsored by the heat treatment committee of the metallurgical society of AIME held at the $112^{\text {th }}$ AIME annual meeting. New-York: Metallurgical Society of AIME, 1984.

[5] Barralis J., Castex L., and Chaize J.C. Influence des conditions de traitement sur la distribution des phases et des contraintes résiduelles dans les couches nitrurées. Mémoires et Études Scientifiques Revue de Métallurgie, 1986.

[6] Jegou S., Barrallier L., and Kubler R. Phase transformation and induced volume changes in a nitride ternary Fe-3\%Cr-0.345\%C alloy. Acta Materiala, Volume 58 , issue 7, April 2010, p.26662676.

[7] Jegou S., Barrallier L., Kubler R., and Somers M. A. J. Evolution of residual stress in the diffusion zone of a model Fe-Cr-C alloy during nitriding. HTM Journal of Heat Treatment and Materials: Vol. 66, No. 3, pp. 135-142.

[8] Dulcy L., Torchane L., Gantois M. Mécanismes de formation et cinétique de croissances des couches nitrurées, Traitement thermique, $\mathrm{n}^{\circ}$ 341, Août-septembre (2002), p.19-26.

[9] Goldschmidt. H.J. Intersticial alloys. Butterworths and Co Ltd, 1967. 